\title{
Using Powerful Tools for Instructional Leadership
}

\author{
Leslie Ann Owen ${ }^{1}$, Maria C. Guilott ${ }^{2}$, Gaylynn A. Parker ${ }^{2}$ \\ ${ }^{1}$ Educational Leadership and Research, Canada \\ ${ }^{2}$ Educational Leadership and Research, United States of America
}

\begin{abstract}
Leaders are expected to be transformational and catalytic. In the $21^{\text {st }}$ Century, expectations on performance are at a record high. The idea of instructional leadership can be a daunting task and often feels like an add-on to many administrators who are working hard wearing a myriad of hats on any given day. By using a human-centered design thinking process to create solutions based on a problem, a question, or a need, through multiple iterations and perspectives, leaders have been able to develop processes that work. The question then becomes, "How does the instructional leader change mindsets that will positively affect learning?" The processes discussed here will provide participants at any grade level or any subject area with specific processes and tools that connect theory to practice and have a high yield in the learning journey whether in a local, provincial, national or a multi-national setting.
\end{abstract}

\section{Introduction}

The purpose of $21^{\text {st }}$ Century schools is to educate future adults who are equipped to handle problems that do not yet exist. Additionally, schools will need to prepare those future citizens to be employed in careers that have not yet been thought of and to live in a world no one can yet fully conceptualize. Simply put, the way leaders create the conditions for learning must change. If leaders are requiring teachers to be designers of learning, it must follow that leaders must also be designers. With that in mind, it follows logically that in order for teachers to be designers of learning, the role of the leader in schools must shift to be characterized by flexibility, adaptability and creativity. Expectations on $21^{\text {st }}$ Century leaders have never been greater. If society wants learning to shift, so must the focus of the leader in the school. It is not enough for them to simply sit on the sidelines any more watching this game. They must now be in the game walking alongside students and teachers to make the necessary changes and to shift the purpose of education to one that is relevant to an unknown future.
The dilemma arises when $21^{\text {st }}$ Century school leaders are expected to provide instructional leadership without practical tools or processes to help them. Consequently, they become good managers and shy away from instructional leadership, which is how they are held accountable in the $21^{\text {st }}$ Century. In order to facilitate out-of-the box thinking necessary to propel learning into hubs of inquiry, both enabling and creative processes must be employed. The research literature has provided some theoretical models that help. However, concrete, ready-to-use models that actually have a high yield and easy applicability are not readily available. This article will focus on three notable processes that are game changers in assisting with these shifts. They are 'show-stopper' processes that move school leaders from their traditional roles as observers, judges, evaluators, and paper shufflers into inquiry-seeking, engaged actors on the school stage committed to real learning for all. These processes are simple to use and are available to leaders who have a desire to create opportunities to improve learning.

If a $21^{\text {st }}$ Century leader wants to affect positive change in the learning, a generative and enabling process is necessary. 'Collegial Learning Walks' is such a process that yields opportunities for principals to shift from a focus on teaching to a focus on learning in the area of instructional leadership. To achieve the shift, leaders must create the conditions for teachers to see themselves as designers of learning, a key and crucial element of the change process.

\section{Foundational Elements}

Lasting change is built on a solid foundation. Several significant and contributory elements served to forge the three processes mentioned in this article. In 1991 a very different approach to design was conceived by IDEO. The process IDEO developed was Design Thinking, which has supported designers worldwide. Design Thinking has since included school leaders and provided tools to develop processes, structures and practices that are easily adaptable, flexible and useful. Using Design Thinking processes, 
whether in their entirety or with help, leaders can solve new or pre-existing problems and challenges. In 1998, the Association for Supervision and Curriculum Development (ASCD) published Grant Wiggins and Jay McTighe's book entitled, Schooling by Design [6]. It was a groundbreaking book that addressed the nature of school, the role of educators, and the role of a mission-driven school environment. Among the assets contained in this book was a backwards design protocol/process for school leaders, a valuable Schooling by Design template that included many of the ideas forwarded by the authors in previous works. Structured in a way to provoke thinking around solving the challenges we face; it is a timeless process that assists in creating the conditions for better decisionmaking. In 2000 The National Academy Press published How People Learn [3], another foundational document to the work included in this article. In 2011 Wiggins and McTighe published The Understanding by Design Guide to Creating High Quality Units [7], which captured key elements used in the processes included herein. In 2005, Philip Schlechty published Creating Great Schools where he noted the difference between true engagement and mere compliance. This work has served to draw attention to the ways in which teachers can engage learners in the learning and warn against reliance on compliance.

\section{A Practical Process and Tool Emerges (Collegial Learning Walks Process)}

In 2008 Dr. Maria Guilott and Dr. Gaylynn Parker [1] developed a process, Collegial Learning Walks, which is totally non-evaluative, yet promotes selfreflection and can become a "game changer" in a school that uses the process with fidelity. With collaboration from Leslie Owen from the Rocky View School jurisdiction in Alberta, Canada, Dr. Guilott and Dr. Parker wrote A Value Added Decision, a book designed to help school leaders improve pedagogy in a non-judgmental and non-punitive manner. The generative ideas promoted in A Value Added Decision were the direct result of continuous inquiry and a need to adapt the processes to the expressed needs of the participants involved. Table 1 from A Value Added Decision is an overall description of the process with a contrast description of what it is not [1]. The book and the ideas promoted gained a following of school leaders that coalesced because they wanted to keep the idea alive and appreciated support from peers.

While the process of collegial learning walks is clearly outlined in the book, it has become increasingly clear it is a process that can also be shifted and shaped to meet the unique culture of any school. Whether a school has brand new teachers or experienced ones, the collegial learning walks process works for all. However, it is important that the leader implementing the process be astute in how he or she creates the conditions for staff buy-in.

Subsequently, a conversation on May 16, 2016, with school leader, Tracy Drummond in the Rocky View School District in Alberta, Canada corroborated the importance of designing this process to meet the needs of the context to improve and adapt the existing processes. In the case of Sarah Thompson School, Ms. Drummond noted how the school had made a fast commitment to Collegial Learning Walks as noted officially in their school education plan. Ms. Drummond was a proponent of the philosophy of collegial learning walks, and was astute enough to know it needed to be adapted to fit the context of their particular school. Comprised of mostly beginning teachers, Tracy took the Collegial Learning Walks and created a series of companion processes so that it would be meaningful to these beginning teachers. In other words, she bridged the learning for her teachers, and they were able to completely understand the process; thus she solicited deeper conversations from them, which ultimately would translate to greater student learning.

Her description of how the process was modified to meet her school's needs validates the idea of focusing on the human element. Ms. Drummond listened empathetically to her teachers and together they designed a process that is fully integrated into the culture of the school. Inquiry embedded in the process centers on how the learning design attends to the stages of learning: Acquisition, meaning making, and Transfer [7].

As a faculty unit, they have clarified what stage is at the center of the design and which pedagogical ideas best support each stage of the learning process. In so doing, the staff has rich intellectual and practical discussions that lead to specific design ideas. Ms. Drummond states that by having these conversations, by engaging in the collegial learning walks, and by participating in the other processes, they are growing as a faculty and are teaching from a growth model. As far as this school leader is concerned, this iteration of the collegial learning walks model, that insists on a self-reflection process totally devoid of judgment, has moved the school forward, opened doors, and enriched learning experiences for the students.

To summarize, the Collegial Learning Walks process involves a very brief ( 5 minute) classroom visit and an immediate debriefing protocol that is totally devoid of judgment. The process is meant for the people on the walk. The truth is the host teacher is not the focal point. In fact, the process does not allow for anything to be written about the brief observation, a total break from traditional practice. This requirement 
alone turns traditional expectations for improving learning completely upside-down. Basically, without deliberately interrupting the flow of learning, the school leader and a group of teachers visit classrooms and talk to students of any age or discipline. Cross-age and cross-discipline visitations are valuable and highly recommended because the focus is on the learning, on the design for learning, and not on the teaching. The group is looking for designs leading to transfer of learning based on the work of Grant Wiggins and Jay McTighe [7] and intended to promote self-reflection. Students are asked a series of questions that are aimed to get after whether they are learning at a deep level and are truly engaged in the process, and are not just compliant. Following a protocol, the group steps out of the classroom and has a discussion about what the students said and about what the visiting group saw during the brief visit. Over and over, teachers and principals alike confirm the Collegial Learning Walks process is one of the best professional learning opportunities they have had the pleasure to engage in because it promotes self-reflection and engages the participants in a dialogue about learning. Everyone involved leaves armed with ideas for what's next as "designers of learning".

Table 1. Collegial Learning Walks Summary. (Source: A Value Added Decision)

\begin{tabular}{|c|c|}
\hline What it is & What it is not \\
\hline $\begin{array}{l}\text { - It is a process designed to look for what's } \\
\text { next in our learning about learning. } \\
\text { - It is a collaborative, generative } \\
\text { professional development process designed } \\
\text { to support everyone's thinking about } \\
\text { instructional practice. } \\
\text { - It is designed to raise questions and } \\
\text { promote self-reflection. } \\
\text { It is a process that will eventually promote } \\
\text { a way of being in an instructional } \\
\text { community, of sharing, of coaching, of } \\
\text { examining practice with no particular } \\
\text { agenda in mind other than improved } \\
\text { learning. }\end{array}$ & $\begin{array}{l}\text { - It is not a process designed to find what is } \\
\text { wrong. } \\
\text { - There are no presuppositions that anyone is } \\
\text { broken or defective in their practice. } \\
\text { - It is not putting anyone on notice of } \\
\text { improvement. } \\
\text { - It is not designed for the implementation of } \\
\text { any particular improvement strategy. } \\
\text { - It is not designed to put anyone's practice } \\
\text { - Inder scrutiny, critique, or improvement. } \\
\text { - It is not a static group or network. } \\
\text { It is not designed to have a focus on a } \\
\text { common "problem or practice." }\end{array}$ \\
\hline
\end{tabular}

\section{Schooling by Design}

The work of Grant Wiggins and Jay McTighe, "Schooling by Design" is a seminal piece of enlightening educational literature that contains specific challenging processes designed for leaders to use. While reading the entire book and following the thinking embedded gives the reader a complete perspective of designing schools that work, it is the Schooling by Design template for leaders that captures the attention and interest of any school group because it is a powerful process that guides conversation using a tight protocol and an efficient use of time. From big idea to specific actionable short- and long-term steps, the process assists in mediating group thinking, creating solid, evidence-based decisions.

The very nature of a school leader's job is isolating. School leaders typically do not want to leave their schools for theoretical models that may or may not work in their school settings. The question arose as to how to build a model that would connect school leaders who wanted to converse and get a global perspective with others but were from different regions in the world.

Employing the power of the backwards design process and with backing from the late Grant Wiggins, the group launched Principal by Design with school leaders from Canada, the United States, Honduras, Ecuador, and Chile who met monthly for one hour each month on Google Hangout, without having to leave their schools to discuss issues of concern.

A preferred model of professional development for school leaders involves their peer group in meaningful, problem-solving conversations. Of particular interest to school leaders is the need to understand how other school leaders address common problems, whether in the same district or better yet across districts or countries. The question of geography separating school leaders who wanted to have conversations with other leaders in similar roles was resolved with the idea of a Virtual International Principal Center. The quest for creating practical solutions for common issues concerning school leaders led to the dilemma of how to create conditions for those who were striving to be 
different in their approach, i.e. $21^{\text {st }}$ Century leaders. To reach a solution, the Schooling by Design template was employed and an interesting development emerged.

Using the Google Hangout feature for face-to-face interaction, the topics were predetermined based upon what leaders were interested in, always providing time to discuss emerging issues. The conversation was robust and interesting for all concerned. One early result from the experience was the knowledge that leaders need a safe mechanism to bounce ideas. As Grant Wiggins said during the group's first meeting, "Everyone needs a friend." The International Principal Center provided a venue for school leaders to vent, to propose ideas, to get feedback on ideas, to co-create possibilities, and to recognize that many of the issues were similar across boundaries and grade levels. In a Google Hangout in August 2013 with the authors of this article, one notable benefit, as identified by Grant Wiggins, was the Principal by Design group got free public relations and strategic advice by quickly examining a situation from a 360-degree perspective and providing each other feedback. Dr. Wiggins noted that, "any meaningful change needs an ideal reached through mission and vision and a comparison of the real against the ideal. The itch for change is the gap between the ideal and the real. Without the ideal and attention to the gap between the real and the ideal meaningful change does not happen." These ideas resonated with the authors and have served to guide future steps in the change process.

A Twitter hashtag was created along with a professional online curation of articles under the name of 'Principal by Design' that posted weekly and still posts to this day. The idea was to provide participants a place to secure peer vetted sites, videos, and articles that had a useful application at the school level. In many cases the leaders took away a sound byte or an interesting concept they all wanted to study further. Schooling by Design precepts and principles were at the core of these monthly discussions, along with Collegial Learning Walks and Design Thinking.

This group met over the span of two years working through issues of interest always reaching suitable solutions. Participation was completely voluntary but the commitment was real. When the facilitator suggested the group not meet because of holidays or busy schedules, the group resisted and asked to continue to meet regardless. In other words, the conversations had real value to the participants. Each person could be totally honest. There was no one to judge and that's what made the process and the international connection so valuable. Many took action in their schools following group conversations. The process worked so well school leaders in Canada decided to re-think the model of supporting $21^{\text {st }}$ Century leadership. They used the design model from
Wiggins and McTighe again to adapt the concept to implement at the jurisdictional level. These processes aided in creating an Instructional Leadership Academy in the Rocky View School District under the direction of Leslie Owen, Director of $21^{\text {st }}$ Century Learning.

They realized they had a challenge to continue instructional leadership development using Collegial Learning Walks as a base to the work and had to adapt to the needs of the group. The sound pedagogical basis, elasticity, and generative quality of the Collegial Learning Walks held tremendous appeal to all that participated. They wanted to keep the instructional leadership process going but realized the need to adapt to each situation. Because the Collegial Learning Walks process was reflective in nature and by design questioned group and individual takeaways each time a learning walk was conducted, the idea of seeking group input lived in the mindset of participants. The Collegial Learning Walks process also sought constantly to improve the protocol and attend to obstacles to implementation and to the prior prejudices that served as the force of resistance. Those implementing collegial learning walks had to overcome the fear resulting from many years of evaluation and judgment. Gaining teacher respect, trust, and confidence in the process was a constant quest of those implementing collegial learning walks. In other words, school leaders who participated in the Collegial Learning Walks process became accustomed to the generative and open nature of the process but mostly to the need to maintain a sense of inquiry and to constantly pursue a better model. One of the premises of the Collegial Learning Walks is that because it is a process, it is never complete and no one holds the answer to the best way to improve the learning process. Everyone's knowing was honored, respected, and trusted thereby supporting teachers, as they became designers of learning. School leaders recognized that solutions to issues/challenges could be "kicked up a notch" or improved significantly when they intentionally used the stages of learning. They also knew that effective use of Understanding by Design tools could lead to better decisions because the process provokes discussion and intentional collaboration with stakeholders. Finally, as was the case with Collegial Learning Walks, Schooling by Design is a journey, not a destination. Consequently, the unstated expectation is that the solution will be iterated as many times as necessary. Interestingly enough, the ideas for instructional leadership generated by the school jurisdiction in Alberta, Canada mirrored the goals and outcomes of the Collegial Learning Walks. School leaders in Alberta asked a series of questions. How might they continue to foster a culture of collaboration? How could they scaffold reflection on experience? And finally, how could they inspire 
creativity? As school leaders and teachers participated in Collegial Learning Walks, they articulated, pursued, and pondered the same questions.

While school leaders thought about next steps, they recognized instructional leadership was the most important role they played as it directly relates to the school's core business. They also recognized instructional leadership is often the most overlooked part of the job and is typically buried under administrative tasks not directly connected to the core business but are "safe" and require little or no commitment or vulnerability. As they learned through the collegial learning walks that each leader would need to become a learner, and that no one held the answer, they also realized how vulnerable that made them. Most people are not comfortable with vulnerability because of the widely held traditional belief that leaders need to have all the answers and are the experts. Even though they saw its value, they initially provided "yes, but...answers" to avoid implementation. When they finally agreed to implement with commitment, they recognized its power and wanted to grow it and adapt it to their own needs. They then began thinking, "What if...?" instead, a question used by designers. They knew that in order to create a culture of innovation, risk taking, improvement, and creative commons, they needed a process that supported teachers as designers of learning.

Dave Morris, Associate Superintendent of Learning for the Rocky View School Division, still subscribes to Schooling by Design and the planning template to this day. He used the process over 8 years ago when he needed a way to reimagine the role of his department. In an interview on May 19, 2016, he commented, "By using this process, it opened up my eyes to the power of visioning through declaring a big idea and working backwards. It was one of the most powerful tools I have used to get generative conversation through a structured process. It is powerful because when you formulate a big idea, it changes the conversation to be one of non-judgment. That first year when we used it, it was hard because it is not how we usually do things, however, when I used it subsequently, the outcome is one that people rallied around. With respect to growing leadership, the process spawned the idea of instructional leadership. I was pleasantly surprised because I always felt leaders needed to have some skin in the game of learning and if the transfer goal and essential questions are framed properly, it can focus and change the conversation. My vision for the Learning Department has always been to create the conditions for better learning for our students. For some time now, I believed the value was in the Professional Development we offered our teachers. Through the process of Schooling by Design, I realized that administrators who identify as instructional leaders are a key piece to the change. Collegial Learning Walks and the various academies that were created from this process made a huge difference in how administrators saw themselves. It shifted their thinking and it has been a key piece to the change. Vehicles such as Learning Walks and Schooling by Design that change thinking around instruction in schools have tremendous power to measure potential and engagement. They have endured in Rocky View and it wasn't a passing fad. That says a great deal about the power of processes that help you to plan from a big idea to action."

\section{Human Centered Design Thinking as Common Practice}

The Design Thinking processes stem from what people normally use to resolve a challenge. Intuitively, most people use the elements. However, the difference is the entire process requires disciplined and divergent minds that work together to seek the best solution for the moment, the people, and the situation. Each step is carefully crafted by the designers of Design Thinking at IDEO to create possibilities that would otherwise never materialize or develop from the challenge at hand. There is no ownership in the solution. The group owns the solution and is expected to question, seek further answers, and iterate, iterate. The Design Thinking process honors the group's thinking, allows for creativity in helpful ways, thus providing assistive tools. Additionally, Design Thinking also recognizes that no idea is ever static. In fact, a working definition is the following:

Design Thinking is human centric in nature. It is designing in a very deliberate way to harness the power of collaborative thinking. The processes and protocols, while rigid, expand possibilities thinking and in the end, powerful human centered design emerges (M. Guilott and L. Owen, 2016).

Actually, Design Thinking consists of five steps: Empathize, Define, Ideate, Prototype and Test. Therefore, the Design Thinking tools employed for inquiry follow a deliberate lock step process and create a menu of possibilities for the school leaders at the Rocky View School District in Alberta, Canada. However, the deliberate steps were not initially obvious to the group.

A fundamental premise of Design Thinking is to know who is at the focus of the design and why. To determine both, there is an empathize component that allows for customization. After using the empathizing tools, the problem can be defined to meet the needs of the client, not the needs of the organization. 
With the success of using collegial learning walks, the group was looking for other inquiry and evidencebased processes that were creative in nature and led to innovative and complete out-of-the-box thinking. Historically, Design Thinking dominated the architectural world and it made its way as an innovative process for any discipline, any problem, and any design challenge. The idea of human centered design led to the publication of Design Thinking for Educators by IDEO.

\section{Theory Translates into Practice}

The group from Alberta was looking for inspiring examples of innovative teaching and learning throughout the world. High Tech High (California), Brightworks (California), and a connection with Telus Spark (Calgary, Canada) spawned a closer look at human centered design thinking. A trip to San Francisco led the group to Stanford University where IDEO principles live. It was also time to rethink the why, the what, and the how of professional learning. The group was open to a design that worked and there was willingness to work through various iterations in the process. They had experienced collegial learning walks, a process that was helping everyone grow in their teaching practice. The process worked well because it had been designed for humans. So often, designs used in educational settings are based on function and are constructed for ease of use and evaluation, not to promote learning in a safe and deliberate way with humans at the forefront of the decision. In order to maintain the momentum brought about by the collegial learning walks, the group searched for ways to continue growing the ideas set forth in collegial learning walks. At the beginning, thinking that travel time for school leaders was a major obstacle, the group tried virtual meetings which allowed them to stay at their schools. However, after applying the empathy process, listening to the client, and being willing to embrace ambiguity, the group decided that travel to a school would be a part of a collegial learning walk process because it met their needs in ways they had not even imagined. A studentproduced video on collegial learning walks entitled Learning Walks at Springbank Community High School and posted on the Rocky View School District website helped everyone involved get a glimpse of the process.

As with the International Principal Center, the big idea was to create space for leaders to have a conversation and call to action around instructional leadership. However, the purpose of the Collegial Learning Walks was broader than just instructional leadership. Its original intention had been to develop teachers into designers of learning through mediated group thinking, discussion, and self-reflection. Keeping in mind the level of isolation school leaders suffer, the idea of time to discuss with clarity nonmanagerial issues was a primary goal. This iteration of the original design had both an online component and a practical component. Google Hangout was still used and the participants had the opportunity to participate in a number of Collegial Learning Walks at different schools and levels. The structure the jurisdiction created was a Fall Academy and a Winter Academy. Participation in the Academy was totally voluntary. Ten leaders participated in each academy that year. Since Google Hangout was the tool used, only ten could participate at one time. The group met online for three sessions and participated in three Collegial Learning Walks at the schools. The design allowed for conversation and planning for the implementation of Collegial Learning Walks in their respective schools.

Success breeds success and the Instructional Leadership Academy was popular enough to run an additional year. The group unanimously wanted to spend more time talking face to face, thereby generating yet another iteration of the original model. The third iteration of the process was totally face-to-face with the primary focus on the dynamic use of Collegial Learning Walks. At the beginning of each Academy, there was time to learn about the process, participate in Collegial Learning Walks and at the end, there was space created for leaders to debrief. Always the intention was an implementation phase for the schools/leaders participating. The adoption of Collegial Learning Walks was and has always been voluntary. However, over half of the participants implemented collegial learning walks on a regular basis as a way of increasing their instructional leadership and promoting the teacher as a designer of learning. As individuals and group members, they gained creative competence as they used design thinking to customize how they implemented Collegial Learning Walks in their respective schools.

After the third iteration, the process became more ubiquitous in the Professional Learning offerings of the jurisdiction. As part of the adoption of the design thinking process in the Rocky View School District, Collegial Learning Walks became a focal point to various site visits across Alberta and the United States in the 'define' phase of design thinking. Virtual learning walks were and still are used as part of the professional growth opportunities for teachers who are learning how to become design thinkers and designers of learning in their respective classrooms.

As leaders became comfortable with Design Thinking, they began to use more and more components, finally learning how to use the process in its entirety. Their goal was to create engaging learning opportunities for students by increasing teacher and 
school administration's capacity around $21^{\text {st }}$ Century learning. With a jurisdiction quite used to using Understanding by Design, it was an opportunity to use the design thinking process they learned through a course from IDEO to increase the capacity for the employment of yet another powerful process. While design thinking is a process where practice is key to understanding, it can feel daunting at first. Working through the process was worth it because the product that emerged from the goal was game changing. In particular, professional learning offerings for school administrators were rich and applicable to growing their skills. Dynamic professional learning opportunities emerged and an iteration of the Leadership Academy became the anchor of the menu. In Design Thinking, a key component is going to see other contexts to help in expanding group thinking. The 'Site Visit Series' invited leaders to think about their context and have an opportunity to see schools that were deemed 'successful' in a particular implementation. Included in this menu were schools near and far from the Rocky View School District. Furthermore, an introduction to Design Thinking was offered as a way to grow the use of the tools. Three Jurisdiction specialists along with the Director and Associate Superintendent of Learning developed an on-line menu to create opportunities for school administrators to think differently about leadership and their role as $21^{\text {st }}$ Century leaders. Additionally, they wanted to further grow teacher practice to be more inquiry based and thought provoking. For example, they promoted the empathy interviews to ensure that solutions were human centered and not institution based. Frequently, school leaders used analogous situations and/or extreme situations as site visits to provoke out-of-the-box thinking. In an analogous situation, leaders could simply borrow the idea and use it almost intact in their particular situations. Often when teachers request to visit teachers who teach their own discipline, they do so in order to adopt ideas from others. The danger is that sometimes adoptions are not a good fit. The Design Thinking protocol can create the conditions for individuals to mediate their own thinking and actually apply the new learning to their own situation. Visits to extreme settings also promote divergent thinking and often lead to sound solutions that have little resemblance to the origin of the idea. Visits to Brightworks and High Tech High in California were idea generating and opened new channels of discussion that could be adapted to individual schools. The idea of site visits had begun with the collegial learning walks. This was used to provoke thinking and generate new ideas in or out of the classroom. Principals and teachers went on site visits to learn and to encourage further inquiry. Another valuable tool that school leaders included in the menu of possibilities was the critical friend protocol designed to encourage sharing and feedback. The "I Wish" protocol kept the iteration process cyclical and the "Rapid Idea Generation" served to inspire creativity.

When interviewed on May 19, 2016, Josh Hill and Dan McWilliam, $21^{\text {st }}$ Century learning specialists who are heavily involved in Design Thinking at the Rocky View School District, recalled that Design Thinking became a focal point in the jurisdiction when the $21^{\text {st }}$ Century Learning Team, coming from different contexts, was drawn to Design Thinking because it merged the shared experience of the group. The reason why it stuck with the team is that each member saw his/her own thinking in the process and it was a model that could be applicable to any context. Before this, the previous work had elements of design thinking but it wasn't intentional. It was in the desire to look for ways to scale out the work that led the group to Design Thinking. The process created the conditions for a shared vocabulary and it was a 'disciplined' creative process. According to Mr. Hill, "It was a way to help me have others come along in the creative process." Mr. McWilliam describes his journey with design thinking as, "Relying on the process rather than getting others to see it my way. I trust the process will get us to where we want to go without coercion or manipulation. Instead of leading people through to my concept of the answer, I led them through the process."

When interviewed on May 18, 2016, Sharon Cronin, principal at the new RancheView School in the Rocky View School District, spoke from a leadership perspective on the opening of a new school. Having already been a part of the processes involved in Schooling by Design and Collegial Learning Walks, the current work with Design Thinking gave her a unique perspective in her work. She noted Design Thinking has impacted her philosophy of leadership. For her as a leader, it has forced her to be a player rather than a coach. Design Thinking compelled her to enter the game. It has challenged her thinking in a positive way about how to best support teachers in moving their practice forward and how to help her staff broaden their thinking. Using Design Thinking in the planning for her staff gave her more tools to help move them and create for these educators a way to think and act as designers of learning. Much like any new initiative, she recognizes she has to shift her perspective. Specifically, a flexible mindset has emerged for her. "This is the process we are going to use as a staff. I too need to be a participant in this process. I need to meet people where they are and help them to broaden their view on how to design learning for the betterment of the students. Many teachers aren't there yet. We are opening up a world of possibilities. However, we need to let those who can't 
see the possibilities yet catch up with the thinking. It is difficult work but well worth it." She further adds, "There is a place for even the most rigid thinkers and all others because it is a multi-faceted process. Everybody wants to do right by students. They want to do their best. My job is to show them there are other ways to do that. It is a fully engaging process and empowers them which, in turn, empowers students."

\section{Moving Forward}

These processes moved even further when high schools in the Rocky View Schools District joined Moving Forward with High School Redesign, an Alberta Education government initiative. The high level of divisional support given to these high schools intrigued personnel at the provincial level. The processes used, namely Design Thinking, with the Collegial Learning Walks as the focal point for leadership growth were notable. Soon after, all high schools in the jurisdiction became a part of this initiative and began to see the face of teaching and learning starting to shift. Since all of the Rocky View Division high schools became involved in the High School Redesign project and were, therefore, part of the mandate from Alberta Education, the school jurisdiction was to provide data to ensure the project was creating positive outcomes. During the first year, Provincial personnel met with large groups of administrators and asked questions but it became very clear while this was rich information, they were not getting into the classrooms to see if positive changes were actually occurring.

Again, this turn of events called for another iteration of the original concept of increasing the involvement of officials at Alberta Education as well as increasing the capacity of the high school administrators who were responsible for the initiative. Leslie Owen recommended to the managers at Alberta Education that Collegial Learning Walks would be a great vehicle for everyone involved to increase their understanding and capacity around what 21st Century learning should be. With approval, Susan Poole, Education Manager, Alberta Education, and Leslie Owen, with the Rocky View School Division, organized a series of Collegial Learning Walks that included various stakeholders with a goal of looking at learning in the classrooms to get a perspective and also to triangulate the data that looked at the following questions, "Is engagement in meaningful learning increasing? How do we know? The process is in its first year of implementation and data will begin to flow as to the level of effectiveness of the initiative and of the process itself. Initial discussions have been overwhelmingly positive. Given the extensive territory covered by the province of Alberta, time and travel presented a challenge. Despite the challenge, the initiative continued to move forward.

Using human centered design thinking coupled with instructional leadership, honors people. This particular initiative has been iterated five times into a better process that fits the needs of the "what's next" instead of "what's wrong." As well, it is fully predicted that there will be more iterations to come.

With respect to leaders, design thinking is a challenge. It is an uncomfortable place when the role of the leader has historically been more managerial in nature. Engaging in this process can be a leap for some as they find it hard to give up the traditional paradigm of what their role has been. The process of design thinking is moving the role of the leader as creating the conditions for release of responsibility and shared vision where power and control are not necessary.

School systems are, by nature hierarchical where the principal holds top billing. When employing design thinking, this hierarchy disappears and leaders must let go of the power. In other words, leadership in the $21^{\text {st }}$ Century is rejecting hierarchical structures inherent in school systems. When times get tough, it is very easy to default to the traditional ways of doing things. One antidote for this tendency is to have critical friends who can assist in moving past the tendency to work from a traditional model and move past the default thinking leaders go to when they feel pressured to conform or change.

\section{Significance to Participants}

The feedback from participants has been overwhelmingly positive as the design for administrator professional development evolved to meet the needs of the participants. The following are comments taken from administrators who participated in the many iterations of the Instructional Leadership Academy.

Susan Poole, former principal in the Rocky View School District in Alberta, Canada and participant in the Instructional Leadership Academy said, "Collegial Learning walks has helped me to understand the importance of the instructional design. If teachers do not know how to design for learning, then it is problematic. For me, I needed to know how to do it. The process helped me to understand it, so I could provide better feedback. Students need to know what they are learning and why. Now, in my work, I constantly look at, 'what is the design', 'how are they engaging students', 'acquisition, make meaning transfer', this is what I look for. The more I do it, the more professional growth there is for me. It provides an avenue to design professional learning that is personalized." 
Heather Fansher, administrator in the Rocky View School District in Alberta, Canada and participant in the Virtual Principals' Academy and in the Instructional Leadership Academy said,

"Having the student voice is vital to understanding student learning needs. Also, the debrief conversations using the protocol as we step out of the classroom are rich in content and insight. These exchanges are powerful as the group comes together to share and learn."

Deborah McLaren, principal in the Rocky View School District in Alberta, Canada and participant in the Instructional Leadership Academy said, "I believe that Collegial Learning Walks is the most powerful initiative in professional learning thus far in the $21 \mathrm{st}$ Century, opening a dimension beyond current bounds of reflection to deepen thinking about one's practice. The way is slow, building trust is paramount, and becoming skilled at facilitating is an ongoing process."

Sharon Rhodes, a principal participant in the Virtual Principal Center said,

"Involvement in our Virtual Principal's Center has given me the opportunity to field questions to colleagues who are in the "trenches". I can bounce situations, ideas, etc. off a group of like-minded peers in a trusting way guided by an extremely knowledgeable facilitator. Sharing of ideas from all over the world puts the realm of education at our

fingertips. When we ponder ideas, questions, and situations together and can speak about it, the synergy created is amazing."

This level of feedback was carefully and regularly examined to be able to improve on the design of the process and better meet participant needs. Each time a change emerged, student engagement in meaningful learning improved.

As stated in A Value Added Decision, [1] the agreements for the collegial learning walks have not changed despite much iteration:

1. We are all learners helping each other improve our own skills

2. No one is "there"

3. We are not here to judge

4. We are not looking for anything in particular, just "effective" instruction leading to transfer

5. We record nothing

6. We refrain from talking to the teacher

7. We maintain strict confidentiality

8. We agree that the only thing over which we have control is the quality of the work we provide our students

\section{Conclusion}

In the $21^{\text {st }}$ Century, now more than ever, leaders need opportunities to think differently. Processes that promote out-of-the-box thinking are difficult to find. The three processes outlined in this article do just that. The Collegial Learning Walks process is designed to focus on the learning and helps leaders to improve their school cultures through the collegiality and deep learning it promotes. The by-product is that leaders increase their instructional capacity. Design Thinking is a process designed to create opportunities for creativity, collaboration and quite simply, leads to a high quality outcome. The process, while it appears simple and unstructured on the surface, is actually very structured. The structure facilitates creativity and a culture of iteration, collaboration, and feedback loops. Schooling by Design is a process that is specifically designed to create opportunities for leaders of schools and jurisdictions to shape discussions and solve problems through goals, understandings, and essential questions (putting the big idea first) and distilling down to the solution and action using evidence-based thinking.

One pearl of wisdom from the book Schooling by Design [6] is the creation of a learning focused mission statement that anticipates outcomes and can be the first step in changing the direction of a school. Whether a school is in corrective action or is already considered "good" by accountability measures of standardized testing, focusing on the school's real mission and then using the process tools described in this article can move the needle for a school's standing and for actual engaged learning at high levels. Attention on learning, not on teaching, is the catalyst that causes a complete paradigm shift that will generate processes, programs, structures, and ideas to prepare all students for $21^{\text {st }}$ Century demands.

The Collegial Learning Walks process works when implemented with fidelity. However, since it is a process, it can be constantly improved by using Design Thinking. Similarly, the Collegial Learning Walks process focuses the group on designing for learning, not on designing for teaching. When the instructional staff comes to that realization, the school becomes a learning place for everyone in the learning organization, and students and teachers alike thrive.

Collegial Learning Walks is designed to get after the learning. Human Centered Design Thinking is a process designed to create collaborative opportunities to solving challenges. Schooling by Design focuses on a big idea and guides the user to use the structure to creatively get at solutions that one might not get to without the process. These processes intersect and weave into each other. They can be used on their own, together, and within each other. 


\section{References}

[1] Guilott, M. \& Parker, G. (2012). A Value Added Decision. Denver, Colorado: Outskirts Press.

[2] IDEO (2013). Design Thinking for Educators Toolkit. https://www.ideo.com/work/toolkit-for-educators

[3] How People Learn: Brain, Mind, Experience and School, (2000). Washington DC: National Research Council

[4] Scott, S. (2002). Fierce Conversations. New York, New York: Berkley Publishing Company.

[5] Schlechty, P. (2005). Creating Great Schools. San Francisco, CA: Josey-Bass.

[6] Wiggins, G. \& McTighe, J. (2007). Schooling by Design. Alexandria, VA: Association for Supervision and Curriculum Development.

[7] Wiggins, G. and McTighe, J. (2011). The Understanding by Design Guide to Creating High Quality Units. Alexandria, VA: Association for Supervision and Curriculum Development. 